value from observations of Mars is $8^{\prime \prime} 78$, agreeing exactly with Michelson's light velocity and the mean constant of aberration. Some other astronomers favour a higher value of the solar parallax, such as $8^{\prime \prime} \cdot 86$; but whichever value we adopt, and whether we prefer Cornu's or Michelson's determination of the light velocity, the conclusion is that there can be no such difference between the group velocity and the wave velocity as 2 or 3 per cent., unless indeed the usual theory of aberration requires serious modification. These considerations appear to me to increase the already serious difficulties, which cause hesitation in accepting the views of Young and Forbes. The advent of further evidence will doubtless be watched with great interest by scientific men.

One other point I may refer to in conclusion. Speculations as to harmonic relations between various spectral rays emitted by a glowing gas proceed upon the assumption that the frequency of vibration is inversely proportional to the wave-length, or, in other words, that the velocity of propagation $V$ is independent of the wavelength, the question now at issue. If the views of Young and Forbes are correct, calculations of this kind must be overhauled. On the other hand, the establishment of well-defined simple ratios between wave-lengths would tend to show that $V$ does not vary.

RAYLEIGH

August 15

\section{ELECTRIC LIGHT IN COLLIERIES}

$\mathrm{A}^{\mathrm{u}}$

GUST 9, I88r, witnessed the first practical application in the United Kingdom of the electric light to the illuminating of coal-mines. The Earnock Colliery, near Hamilton, Lanarkshire, belonging to Mr. J. Watson, has been fitted with Swan's incandescent lamps specially arranged with outer lanterns of stout glass, air-tight, and provided with steel guards. The workings in which the lamps were fixed are 118 fathoms, or 708 feet below the surface. Twenty-one brilliant little lights placed at the pit-bottom, in the roads, and at the actual face of the seam where active operations were in process, supply an illumination of a very different character from the dismal glimmer of an occasional Davy. The electricity was generated by a dynamo-electric machine at the surface worked by a special i 2 horse-power engine, and conveyed by two cables, first along telegraph poles to the pit mouth, then down the shaft to the workings, in one section to a distance of half a mile. The overhead wires are naked copper wires of $\frac{3}{8}$ inch diameter, while those below ground are carefully insulated, and in the shaft are protected with an outer tube of galvanised iron. At suitable points of the circuit safety air-tight switches, the invention of Messrs. Graham of Glasgow, are inserted to afford control over individual lamps. The mine was visited two days after the installation of the light by members of the Mining Institute of Scotland, with whom was Mr. W. Galloway, whose remarkable experiments on the explosive effects of coal-dust will be remembered in connection with the more recent report of Prof. Abel. The party were photographed in the workings. An experiment was made with a lamp to test whether in the event of its being broken by accident a surrounding atmosphere of explosive gas would or would not be kindled by the strip of red-hot carbon before it had had time to cool. Into a box containing about three cubic feet of explosive gas a single lamp, removed from its outer protecting case of stout glass, was placed, and the current was turned on. The fragile bulb inclosing the incandescent carbon thread was then purposely broken, when the gas inclosed in the box immediately exploded. No such occurrence could possibly happen if the protecting case of stout glass is properly constructed. The risk of accident must be considered as immensely less than that of the ordinary Davy lamp, especially when it is remembered that with the brilliant light of the electric lamps they need no longer be carried in the hand or set down upon the floor near the actual spot where the coal is being got, but will be fixed overhead at a safe distance against the wall of the mine. The ease with which the light can be turned out during the firing of a blast is another point in their favour. The proprietor of the Earnock Colliery is greatly to be congratulated on the step he has taken. In 1880 the death-roll of the slain by explosions of fire-damp in Great Britain reached the figure of 499 persons. We venture to predict that the universal adoption of electric lighting in fiery mines would reduce this figure to one-tenth of its terrible proportions. How many years will it be, we wonder, before the adoption of electric lighting will be made compulsory by Act of Parliament? And how many colliery owners will discover, we would ask, when driven to this course by compulsion, that in the long run they effect an economy by discarding the clumsy and unsafe "safety"-lamp, which will so soon be numbered with the "flint mill" amongst the relics of the past?

\section{SINGULAR STONE HATCHETS ${ }^{\circ}$}

$\mathrm{M}$ ONSIEUR PITRE DE LISLE has lately called attention to a singular class of stone celts or hatchets which have for the most part, if not indeed only, been found in Brittany and North-Western France.

These hatchets, instead of tapering away to a more or less conical point at what has been termed the butt-end, suddenly expand close at that part, so as to present a somewhat button-like termination. In one instance, at least, the hatchet ends in a spheroidal ball not unlike that which one occasionally sees on the horns of cows which are inclined to make too free use of their natural arms of offence. In the case of the hatchets, however, the button is at the opposite end to that which was in use for cutting. These blades vary in length from about three inches to as much as fifteen inches, and are all made of rocks belonging to the family of Diorites, principally of Aphanite.

M. de Lisle has given to these instruments the name of "haches à tête" or "haches à bouton," and has pointed out the similarity which in some respects they bear to hatchets of Carib origin and to the merés of New Zealand. In these instances the object in view in forming a projecting rib round the end of the blade was no doubt to afford the means of preventing it from slipping out of the handle or hand which held it. He thinks that the same object led the makers of these French blades to adopt the same form, and that the hatchets, after passing through a transverse hole in their hafts, were secured by cords wound around them, which abutted against the projecting rims at their small end. In his opinion there is a representation of this method of hafting to be seen among the sculptures on the dolmen of Mané-Lud.

It is a remarkable circumstance that the hatchets of this particular form appear to be restricted to so small a district of France, and not to occur elsewhere. M. de Lisle is in consequence inclined to assign the development of this type to a late period in the Neolithic age, and has offered some reasons for inferring that in Brittany the use of bronze hardly found a home, and that stone was the principal material employed for cutting tools when first that part of Gaul was brought in contact with Roman civilisation. It seems probable enough that in that as in other countries there were districts which lay far away from the principal bighways of progress and civilisation, and where old-world usages prevailed long after material advances had been made in more fortunate but not very distant regions.

We may however be allowed to doubt whether the country of the Veneti, the most enterprising maritime tribe of Gaul, whose ships in the days of Julius Cæsar were already provided with chain-cables of iron, were I "Les Haches à Tête de la Pretagne, etc." (Nantes, 188o.) 